\title{
La obra institucional por la autonomía es una historia de migración. De Socialisme ou Barbarie a Cornelius Castoriadis / Agora International
}

\author{
Rafael Miranda Redondo
}

Este artículo es un intento por replantear la dimensión imaginaria como espacio para la transformación social. Frente a la tradición filosófica heredada y su dependencia de la hipercategoría de la determinidad, revisitamos una diáspora en torno a la figura de Cornelius Castoriadis, comprometida con un proyecto político radical. La crítica del fenómeno burocrático había tenido lugar en el espacio del colectivo y la revista Socialisme ou Barbarie. Un ejercicio fuertemente inspirado en el saber psicoanalítico nos permitirá establecer un paralelismo entre la obra institucional por la autonomía, la dimensión imaginaria y social del desplazamiento y una manera nueva de entender el servicio público.

PALABRAS CLAVE: dimensión imaginaria, diáspora, cultura política, alteridad, obra institucional, servicio público

Instituting for Autonomy Is a Testimony of Migration. From Socialisme ou Barbarie to Cornelius Castoriadis I Agora International

This is an attempt to reframe the imaginary dimension as a space for social transformation. Against the inherited philosophical tradition and its dependency of hypercategory of determination, we revisited a diaspora around Cornelius Castoriadis, committed with a radical political project. The bureaucratic phenomenon criticism takes place in the group and the magazine Socialisme ou Barbarie. An exercise, strongly inspired in the psychoanalytic knowledge will allow us to establish a parallelism between the institutional work for autonomy, the imaginary and social dimension of the displacement, and a new way to understand public service.

KEYWORDS: imaginary dimension, diaspora, political culture, otherness, institutional work, public service

Rafael Miranda Redondo: Colectivo de Bibliógrafos de Cornelius Castoriadis / Agora International, París, Francia alloiosis@hotmail.co.uk 


\section{INTRODUCCIÓN}

$\mathrm{A}$ 1 recibir la invitación de Desacatos para participar en este panel me tomó por sorpresa que se me solicitara retomar el tema de las migraciones contemporáneas. Además de que la migración constituye un elemento de mi propia biografía y hace años me ocupé de ella desde la academia y la acción social, hacía tiempo que no le dedicaba un esfuerzo de reflexión consistente. Los términos de esta invitación se tradujeron en una ocasión para regresar sobre una visión crítica respecto de un tópico que se ha puesto de moda en ambientes bien pensantes - sectores de iglesias, universidades privadas en particular y medios humanitarios y asociativos varios-.

Es cierto que hoy muchos se sienten con autoridad para escribir sobre migración, incluso aquellos que nunca han migrado. Ésta es una excelente oportunidad de exponer lo que provocó mi distanciamiento de un análisis supuestamente aséptico, sis que, cautivado por la ilusión constitucional y por el puro estado de ley, ${ }^{1}$ hoy es compartido por sectores marxistas y liberales en medios humanitarios. Se trata de una versión políticamente correcta del fenómeno que da la espalda - no casualmente como veremos- al sujeto posible —en la terminología propuesta por la convocatoria de Desacatos- que habita todo migrante ${ }^{2}$ y cancela la posibilidad de la política en sentido noble, alimentando el asistencialismo y la filantropía, una postura que cancela la gran política, es decir, el locus en donde las sociedades de origen y destino se autoalteran transformando sus propias instituciones. De esta versión del

\footnotetext{
${ }^{1}$ Véase la lista de convenciones internacionales sobre el tema, el dinero invertido para pagar funcionarios y consultores y el casi total desinterés por ponerlas en práctica por parte de los gobiernos firmantes.

${ }^{2}$ Véase el Congreso Internacional Formas del Exilio, organizado por la Universidad de Ca’Foscari de Venecia con la Regione Veneto en Italia a finales de 1995. Los materiales fueron recogidos en el número 26-27 de la revista extinta Archipiélago, Cuadernos de Crítica de la Cultura bajo el mismo título en 1996.
}

fenómeno, funcional al estado de cosas, me ocupo en la primera parte de este artículo.

Enseguida, ilustro mi distanciamiento respecto de la manera en que la institución de la migración habla, introduciendo material etnográfico y delineando un dispositivo de tratamiento alterno del fenómeno migratorio. A partir de aquí me separo paulatinamente de las consideraciones más genéricas y expongo la historia de migración de un colectivo anónimo concreto. Sujetos migrantes que hacen institución en términos del proyecto de autonomía. ${ }^{3}$ Se trata sobre todo, aunque no solamente, de la historia de migración de Cornelius Castoriadis en su condición de miembro fundador de Socialisme ou Barbarie ( $S$ ou $B)$, el colectivo y la revista. ${ }^{4}$ Después describo aspectos de la trayectoria de la Asociación Ley 1901 -fundada a posteriori por un colectivo de migrantes en Francia-, denominada Agora International, y de su compromiso a través de la puesta en operación del portal electrónico Cornelius Castoriadis/Agora International (CC/AI). ${ }^{5}$ La glosa de los pasajes de las trayectorias descritas me permitirá puntualizar el dispositivo que presumo novedoso respecto de las modalidades del desplazamiento humano. Finalmente, ahondaré sobre algunas nociones que he desarrollado a raíz del distanciamiento mencionado para abrir, presumo de nuevo, futuros desarrollos.

\section{LA INSTITUCIONALIZACIÓN DE LA MIGRACIÓN}

Es banal decir que la migración es vieja como el hombre en el sentido del anthropos. Su dimensión espacio-temporal ha dejado rastros en prácticamente

\footnotetext{
${ }^{3}$ Recientemente se llevó a cabo un coloquio de impronta francosueca sobre el aporte de la inmigración griega "comprometida", particularmente Cornelius Castoriadis, Kostas Axelos, Kostas Papaïoannou, a la cultura política francesa en la segunda mitad del siglo xx. Para más información, véase $<w w w$.franskaspraket. eu/spip.php?article66>.

${ }^{4}$ La revista tenía por subtítulo Organe de critique et d'orientation révolutionnaire [Órgano de Crítica y Orientación Revolucionaria]. ${ }^{5}$ Véase <www.agorainternational.org/es/index.html>.
} 
todas las sociedades históricas. Esos rastros, a pesar de los efectos perversos del determinismo en la tradición filosófica heredada y en consecuencia en las disciplinas sociales, han dado cuenta de la dimensión imaginaria de todo desplazamiento. La migración, en sus manifestaciones, se ha acompañado igualmente de guerras y mestizajes, falsos o verdaderos. Como suele ocurrir con todos los movimientos sociales, ese fenómeno también ha pasado de ser instituyente a ser institución, es decir, un entramado complejo de significaciones imaginarias sociales, en apariencia dadas de una vez y para siempre.

En este proceso de institucionalización se han formulado nociones como migración forzada o planteamientos tan polémicos en la práctica como el de sociedad multicultural. Los antecedentes de la discusión sobre la migración pudieran encontrarse en épocas muchísimo más lejanas de las que se tiene registro, a pesar de que fue en los años treinta del siglo pasado cuando las ciencias sociales y el diseño de políticas públicas empezaron a dar cuenta del fenómeno. Los vínculos que pudiera haber entre los orígenes de la migración como temática y su paulatina institucionalización con la génesis de la ciencia antropológica en la experiencia colonial nos hacen presumir un proceso fundacional remoto. En la contemporaneidad, es a partir de la experiencia de la Guerra Civil en España, seguida de los horrores del Holocausto, que la denominada comunidad internacional iba a formular una propuesta de Convenciones inspiradas en los derechos humanos referidas al fenómeno migratorio. La última oleada de españoles llegó a México antes de que ese aparato institucional se desplegara. En ese proceso de diáspora intervino - en un contexto internacional de abandono de los defensores de la república por parte de las grandes potencias, principalmente europeas-, además de las fuertes convicciones de los antifranquistas, la vigencia de un proyecto de sociedad distinta. La gran política de por medio en ese proceso, hoy tan disminuida, había dictado que dicho proyecto de sociedad, entonces amenazado por el totalitarismo, hiciera sentido para otros pueblos.
En ese contexto de institucionalización de la migración, al inicio de la década de 1990, tuve la oportunidad de hacer una intervención en algunos países de América Central. Presento algunos pasajes de la etnografía de esa experiencia, importantes para lo que quiero argumentar.

La tarea para esa "consultoría" era registrar la evolución del fenómeno migratorio en la región que después del conflicto armado de la década anterior se encontraba en una situación menos volátil. Me propuse dar cuenta de dicha evolución con un trabajo de entrevistas en profundidad con informantes clave que provenían de sectores civiles, de organizaciones políticas diversas, de gobierno y de la cooperación internacional. La recepción del reporte de los organismos que formularon el encargo $^{6}$ fue poco entusiasta, por decir lo menos. Los términos del desencuentro giraban en torno a mi escepticismo frente al alcance explicativo de la noción de migración forzada y particularmente respecto de las consecuencias negativas de su aplicación en el plano político. En efecto, pensar que el acto de desplazamiento era sólo un reflejo reactivo ante la fuerza, ausente de voluntad, llevaba a la pregunta: ¿por qué los afectados por ese imperativo no migraban al unísono?

La etnografía de esa intervención nos decía que - precisamente-, a pesar de que un número importante de poblaciones habían sobrevivido al imperativo de la guerra y la violencia, sólo una minoría decidió migrar. ${ }^{7}$ Esta constatación me hizo interrogarme sobre una cierta funcionalidad de la noción de migración forzada para la institución de la migración. La literatura sobre el análisis de la implicación (Lourau, 1987) y la que se refería a los niveles

\footnotetext{
${ }^{6}$ Inter Pares de Canadá, el Consejo Danés para Refugiados (DRC, por sus siglas en inglés) y Ayuda Sueca a Refugiados (swera, por sus siglas en inglés), reunidos en la Consejería en proyectos. Véase $<$ www.pcslatin.org/pcs.htm>.

${ }^{7}$ Otra situación que ilustra lo que sostengo es la gran cantidad de españoles comprometidos con la república y la revolución que a pesar de la derrota de ésas permanecieron en la península. La experiencia chilena después del golpe contra Allende es otro ejemplo.
} 


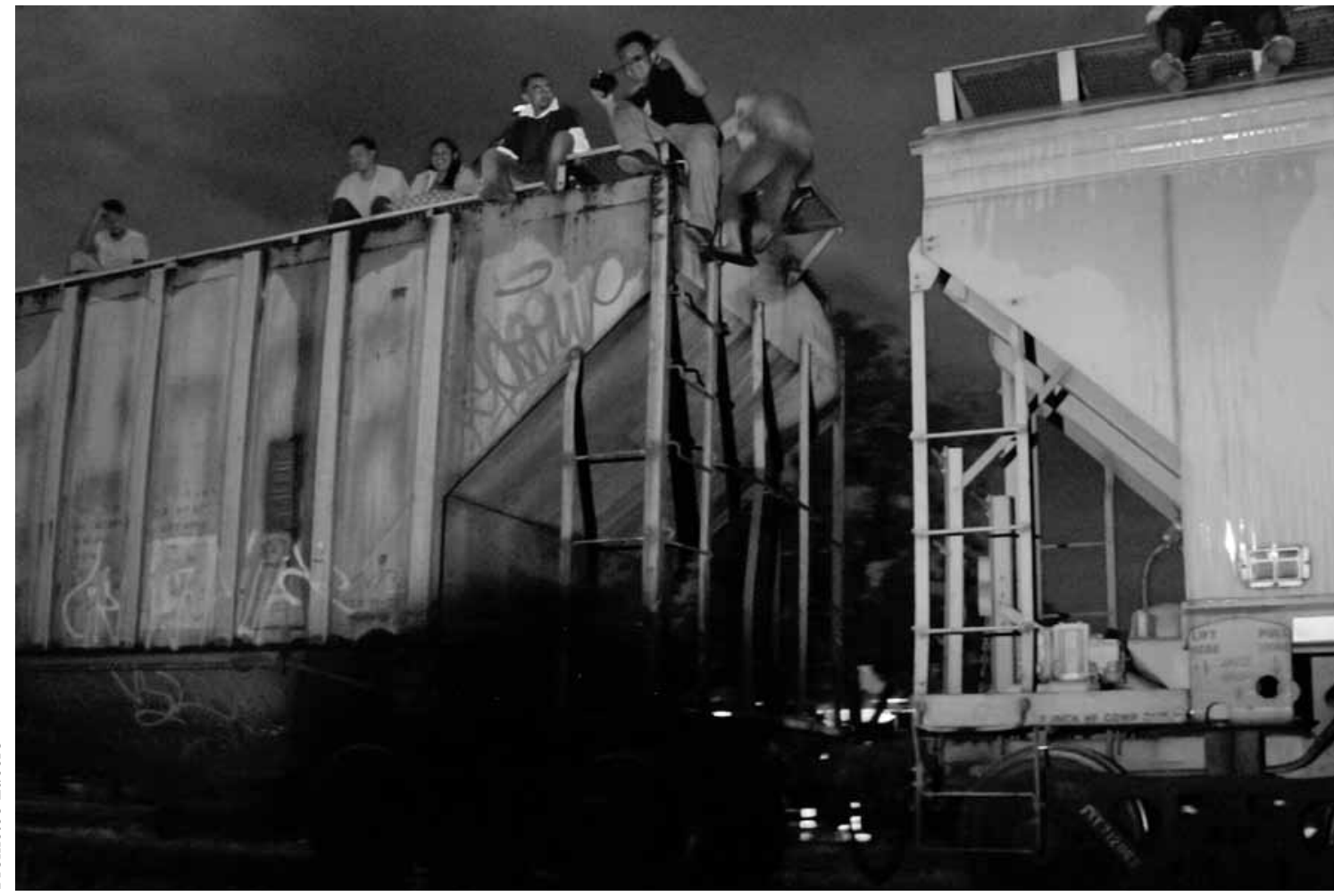

Migrantes abordan el ferrocarril en Ixtepec, Oaxaca, hacia Estados Unidos, septiembre de 2011.

transferenciales y contratransferenciales ${ }^{8}$ dentro de las organizaciones me habían facilitado la tarea. Básicamente estaba de por medio ese trayecto que tanto el liberalismo como el marxismo - este último en versión latinoamericana, estrechamente vinculado con la teología- han recorrido y que consiste en establecer una norma de normas, negando así la perpetua alteridad del ser y de la historia. Me explico.

\footnotetext{
${ }^{8}$ Términos de inspiración freudiana. Parafraseando a Castoriadis, la transferencia es un estado regresivo del sujeto que, en la escena del análisis, enviste al analista del odio y el amor hacia la figura parental. La contratransferencia sería todo aquello que el analista pone en juego para resistir y hacer uso de la transferencia de la que es objeto por parte del analizado. La corriente institucionalista, apoyándose en el concepto de institución de Castoriadis, habría hecho un interesante aporte al explicitar cómo las significaciones de padre o madre, en su dimensión institucional, permiten hablar de transferencia al abordar la relación entre las instancias de lo instituyente y de lo instituido. Véase Deveraux (1980).
}

Fue a raíz de la intervención en América Central que pude sopesar las consecuencias, devastadoras en el plano político, de la funcionalidad para la institución humanitaria del concepto de migración forzada y del diseño de políticas públicas que deriva de él. Los "migrantes forzados" eran las "víctimas" perfectas para los programas asistenciales y la reproducción al infinito de los establecimientos benefactores, "apolíticos", "humanitarios", "filantrópicos".

Este equívoco - que en versión marxista leninista había hecho de los obreros sujetos revolucionarios que no se saben como tales y que lo son incluso a pesar de su voluntad- había trasladado, gracias a algunos malabarismos, esa condición per se hacia los campesinos empobrecidos e indígenas. Es el mismo equívoco, por decir lo menos, que asignaría a los migrantes la condición — determinada de una vez y para siempre- de entes pasivos, en virtud de las leyes de la historia ante 
las cuales no hay nada que hacer porque ya han decidido por ellos y dicha decisión les sería comunicada. El dramatismo de los procesos de sentido que prosiguieron a los desengaños de ese equívoco, para mentes más o menos bien pensantes, todavía hoy nos ilustra cuando los migrantes no hacen lo que debieran hacer. Regresaré a esto más adelante.

Ante este panorama y precisamente a contracorriente de esa tendencia a disecar los fenómenos - gracias a principios inamovibles que no funcionan cuando está de por medio la dimensión imaginaria-, el segundo punto polémico de mi reporte era la conclusión de que la decisión de migrar está mediada por un acto condicionado, es cierto, pero también voluntario en infinidad de casos. Sus móviles rebasan la simple reacción ante el imperativo - ya sea que éste provenga de un Estado, un desastre natural o un deseo de aumentar los ingresos para salir de la miseria-. El elemento más polémico y más difícil de avalar fue que en un sinnúmero de casos el desplazamiento conlleva un distanciamiento reflexivo más o menos explícito en relación con las instituciones de origen. Este aspecto desentonaba terriblemente con la versión oficial de la migración institucionalizada. La constatación nos decía que los migrantes no eran menores de edad ${ }^{9}$ y que muchos de sus actos - políticos o de puesta en entredicho de facto- daban cuenta de una toma de posición respecto de las instituciones, de la política en sentido noble, del momento en que nos preguntamos sobre las significaciones imaginarias sociales que están en nuestro origen.

Estos dos aspectos que destaco en líneas anteriores - por un lado, la relatividad de la noción de migración forzada con la consecuente denegación de la dimensión imaginaria de la sociedad y, por otro, los procesos de sentido que conlleva el desplazamiento respecto de las instituciones propias- me llevaron a explorar un camino alterno. El trabajo durante los años que sucedieron a la época en que

\footnotetext{
9 "Necesitados" en todo momento de expertos y consultores que cobran sumas millonarias para que "faciliten la resolución de sus problemas".
}

me ocupé de las migraciones, y una vez constatado lo que describo en líneas anteriores, se dirigió a analizar la dimensión imaginaria, en los grupos y en las instituciones, en particular para el caso de aquellos sujetos que se habían propuesto "aliviar a la sociedad" del "drama" migratorio. Expongo a continuación algunos elementos de esta reflexión.

\section{Migración: continuidad o cambio}

El trabajo en torno a una visión alterna del fenómeno migratorio se fue concretando en un dispositivo armado desde la relectura de la obra castoridiana y con base en la consideración de su influencia en la corriente institucionalista. Dicho dispositivo tuvo un proceso de maduración gracias a la intervención prolongada en la Association Appartenenances. ${ }^{10}$ Dicho dispositivo había integrado de manera meridiana el concepto y la práctica de la autonomía y se orientaba a acompañar la acción autorreflexiva de los equipos de estudio involucrados. ${ }^{11}$

En el transcurso de esta experiencia fueron emergiendo algunas nociones parcialmente tomadas de otros autores y eventualmente desarrolladas en algunos de sus aspectos más novedosos. Por un lado, trabajé la noción de obra institucional, gracias a los aportes del análisis de la implicación; por el otro, me dediqué, también en mi proceso paralelo de escritura de tesis doctoral, a analizar la noción de alteridad. El desarrollo de una práctica analítica institucional, que he denominado clínica de la alteridad, debía permitirme con el paso del tiempo y la integración de la experiencia dar cuenta, en los grupos y en las instituciones, del curso de la obra institucional por la autonomía.

Una vez introducidos esos elementos de la génesis histórica de mi propuesta, lo que viene a continuación aspira a ejemplificar un ejercicio de dicha clínica.

\footnotetext{
${ }^{10}$ Véase <www.appartenances.ch $>$.

${ }^{11}$ Básicamente, gracias a la animación de los seminarios Appartenance, autonomie et haine de l'autre.
} 
En este caso procedo aplicando ese dispositivo al análisis de la historia de migración de ese miembro fundador del colectivo y la revista $S$ ou $B$ que fue Castoriadis. Mi objetivo consiste en dar cuenta de los efectos analizadores de ese trayecto para la institución de la cultura política de la extrema izquierda en la Francia de posguerra. De manera intencional, quiero dejar anotados dichos efectos para el universo de significaciones en el que la "migración forzada” surgió y se hizo institución.

\section{AUTO-ALTERARSE PARA TRANSFORMAR A LA SOCIEDAD}

Es cierto que desde la perspectiva que concede un rol preponderante a la dimensión imaginaria es posible vivir las aventuras más intensas y los desarraigos más escalofriantes sin salir de casa. La antropología había anotado una versión de ese debate al hacer de la etnografía un extrañamiento vo- vino la discusión en torno a si es posible ponerse en los zapatos del otro, porque si otro es yo, yo es otro y así sucesivamente. La ilusión de no contaminar los procesos de intervención inspiraba esta vía, maquillando - por momentos- el acto antropológico con una especie de iluminación inmaculada. Para el exilio etnográfico de quien concibe la alteridad, lo mismo que para el estudio de lo que se denomina "migración" en el lenguaje corriente — es decir, el desplazamiento en el espacio geográfico-, están en juego una infinidad de variantes imaginarias y social-históricas, ligadas a los móviles sentidos que una corriente de psicosociología ha llamado y analizado bajo el denominativo de implicación. Las mentes bien pensantes de la academia nos habían dicho que se migra porque la situación en el lugar de origen "es inaceptable", porque se es "objeto de persecución", porque es el ritual de transición para "ser hombre" en las comunidades tradicionales o que se migra para consumir más. A menudo, los móviles ocurren de manera simultánea y los procesos de sentido que acompañan todo desplazamiento se hacen más complejos. Veamos estas consideraciones para un caso específico.

\section{Una singular trayectoria}

Para ilustrar la complejidad que supone mi hipótesis respecto de la migración condicionada, pero no forzada, hago uso de algunos pasajes de la historia del migrante griego Cornelius Castoriadis. El trayecto migratorio y la obra institucional que lo acompaña lo reivindicaron como especialmente ilustrativo de los aspectos que hacen de la migración, incontestablemente, un proceso de sentido ni forzado ni determinado. La obra que aquí me ocupa iba a plasmarse en el hacer instituyente del colectivo denominado Socialisme ou Barbarie. Revisemos algunos datos biográficos para después describir propiamente la trayectoria del grupo.

Castoriadis nació en Constantinopla y fue llevado a Atenas antes de cumplir un año de edad y ahí vivió hasta su primera juventud. Es interesante considerar la investidura que le imprime al enorme afecto que sus padres sentían por él, particularmente en cómo lo evoca, ${ }^{12}$ para referirse enseguida a sus vocaciones prematuras por la filosofía, la música y la política. Una madre amante de la música y un padre ferviente "voltaeriano" y ateo practicante —además de apasionado por la política- daban un sello al universo de Castoriadis. Durante su juventud su padre ${ }^{13}$ fue expulsado del territorio francés - por su injerencia, en tanto que extranjero, en asuntos políticos-, lo que representó un evento definitivo. La fase sucesiva fue la introducción a la filosofía ${ }^{14}$ y a la política radical cuando todavía era adolescente.

\footnotetext{
12 Véase <www.agorainternational.org/es/esccaiint.pdf $>$.

${ }^{13}$ No obstante su abierta francofilia.

${ }^{14}$ También a la teoría social. Castoriadis traduce a Weber del alemán al griego a los 17 años.
} 
Castoriadis llega a Francia en 1949 gracias a un programa promovido por el Instituto Cultural Francés de Atenas ${ }^{15}$ y en particular por la gestión - muy de izquierda, según narra el entonces becario del gobierno francés - de Octave Merlier. El testimonio del barco que lo conduce al hexágono sugiere una auténtica diáspora generacional ${ }^{16}$ de jóvenes llenos de inquietudes compartiendo su oposición a la dictadura de Metaxas. No pasará mucho tiempo antes de que Castoriadis abandone su proyecto de tesis de doctorado porque "había cosas más urgentes que atender". Un primer acercamiento y un extrañamiento inmediato respecto del ámbito académico francés de la época había precedido su vínculo con los ambientes de la izquierda extrema en ese país, en concreto con el trotskismo y el Partido Comunista Internacionalista (PCI). La fundación de la tendencia Montal-Chulieu - seudónimos de Claude Lefort y Castoriadis - al interior de éste constituyó la génesis del grupo y la revista legendarios que llevaron el nombre de Socialisme ou Barbarie (19481967). Según los datos que Gottraux $(1997,2002)$ proporciona, además de Castoriadis, participaron en esa experiencia - al lado de los franceses- Jackes Signorelli, italiano; Benno Sternberg, rumano; Tamao ( $i$ ?) - Gottraux, basándose en testimonios orales, refiere este nombre e incluye los signos de interrogación presumiblemente debido a una imprecisión de la transcripción-, polaco; Alberto Vega, catalán; Sebastien de Diesbach, suizo; Helen Arnold, estadounidense; Enrique Escobar, español, y Gustave - seudónimo-, judío polaco. En el contexto más general inmediato anterior a la creación de $S$ ou $B$ en Francia, la liberación de París por la Segunda División Blindada, bajo las órdenes del general Leclerc ${ }^{17}$ e infinidad de células de la resistencia francesa (Reynaud, 2007), habían dado cuenta de la

\footnotetext{
${ }^{15}$ Equivalente al Instituto Francés de América Latina (IFAL) en México.

${ }^{16}$ Algunos nombres: Kostas Papaïoannou, Kostas Axelos, Georges Kandylis.

17 Véase <www.liberation.fr/cahier-special/0101499594-les-antifranquistes-a-l-avant-garde $>$.
}

participación - si no exclusiva entre los extranjeros-, sí mayoritaria por parte de españoles antifranquistas refugiados en Francia, muchos de los cuales fueron capturados y trasladados a los campos de la muerte. ${ }^{18}$

\section{CREACIÓNY AUTODISOLUCIÓN DE S OU B}

El primer registro que conocemos de la consigna socialisme ou barbarie proviene de Marx y Engels (1848) en el "Manifiesto del Partido Comunista": ;Socialismo o recaída en la barbarie! $!^{19}$ La posibilidad de que todo sistema racional contenga una contradicción y el germen del fenómeno burocrático - presente desde el proyecto de tesis que lleva a Castoriadis a Francia- desembocará en una primera formulación respecto de la significación imaginaria social del dominio racional. Esta reflexión, más que una consideración de orden académico, tiene lugar a partir de lo que con el tiempo el autor denominará el hacer pensante. En referencia a un pasaje de su biografía política, Castoriadis nos dice:

Yo había descubierto al mismo tiempo la filosofía y el marxismo cuando tenía 12 años, y me adherí a la organización ilegal de las Juventudes Comunistas, bajo la dictadura de Metaxas, cuando me encontraba en el último año del bachillerato, a los 15 años. Pasados algunos meses, mis camaradas de célula (quisiera dejar anotados aquí sus nombres: Koskinas, Dodopoulos y Stratis) fueron detenidos, pero, a pesar de

\footnotetext{
${ }^{18}$ Véase el tristemente célebre "campo de los españoles", Mauthausen, a raíz de la disposición de Franco - en el sentido de que "no había españoles fuera de España"-. Mientras que en España se consolidaba la dictadura, 35000 españoles participaron en la Guerra Mundial con los aliados y aproximadamente 10000 de ellos acabaron en los campos de concentración alemanes.

${ }^{19}$ Subrayado en el original. El párrafo completo dice: "En el momento actual, el socialismo es el último salvavidas de la humanidad. Por encima del edificio resquebrajado de la sociedad capitalista, se observa destellante, en letras de fuego, el dilema profético del Manifiesto del Partido Comunista: ¡Socialismo o recaída en la barbarie!". Véase <www.marxists.org/francais/luxembur/spartakus/programme.htm>.
} 
que fueron torturados salvajemente, ellos no me denunciaron. [...] Descubrí rápidamente que el Partido Comunista no tenía nada de revolucionario, sino que era una organización chovinista y burocrática (hoy diríamos una micro sociedad totalitaria). ${ }^{20}$ Después de una tentativa de "reforma" junto con otros camaradas, que evidentemente fracasó, lo dejé y me adherí al grupo trotskista más a la izquierda, dirigido por una figura inolvidable de revolucionario, Spiros Stinas (Castoriadis, 1996a: 82). ${ }^{21}$

La ruptura con el PCI, una vez fuera de la Grecia de su primera infancia y juventud, y la creación del grupo $S$ ou $B$ se originan a raíz de la fuerte crítica que Castoriadis y Lefort realizan en el seno de ese partido:

yo había desarrollado una crítica de la concepción trotskista del estalinismo desde 1944-principios de 1945 [...] [que estaba comprometida] a verla [la burocracia] no como un "estrato parasitario" sino claramente como una clase dominante y explotadora [...] (Castoriadis, 1974: 1-2).

Desde su punto de vista, lo que estaba en el origen de la postura que ve a la burocracia como un "Estado obrero degenerado" es todo un universo de desarrollos teórico-políticos, ligados a la tradición marxista, a sus destinos ciegos, ${ }^{22}$ y finalmente a la ontología determinista que le subyace. El debate que acompaña a esa polémica ${ }^{23}$ tuvo el mérito de anunciar, con

\footnotetext{
${ }^{20}$ Las cursivas son nuestras.

${ }^{21}$ Agis Stinas o Spiros Stinas (1900-1987). Este revolucionario griego, cuyo nombre verdadero es Spyros Prifitis, fundó el Partido Socialista Obrero griego (SEKE), que se convirtió en el Partido Comunista de Grecia en 1924. A partir de 1947, Stinas sería el principal representante del grupo $S$ ou $B$ en Grecia. Al final de su vida pública sus Memoires, 60 ans sous le drapeau de la Revolution (1990) fueron publicadas en Atenas y reeditadas en revistas de orientación libertaria. Véase <bataillesocialiste.wordpress.com/ biographies/stinas-1900-1987/>

${ }^{22}$ Revísese la condena del socialismo yugoslavo por no haber colectivizado (Castoriadis, 1974: 3) y, por tanto, por ser contrario al principio según el cual "la colectivización - véanse las nacionalizaciones en nuestros días en América Latina por parte de dictaduras "de izquierda" - es equivalente al socialismo".

${ }^{23}$ Debate gracias al cual se conoce a Castoriadis y a $S$ ou $B$ en medios académicos.
}

una importante anticipación, la realidad del capitalismo burocrático y de su vocación totalitaria. Ese debate, al privilegiar la división entre dirigentes y ejecutantes, hace una crítica sesuda del fenómeno burocrático y emprende una reflexión que rebasará con creces el tradicional análisis de clase.

La separación de la dirección y de la producción inmediata, el desplazamiento de la dirección de la actividad de trabajo a una instancia exterior al trabajo y al trabajador; la seudo "racionalización"; el "cálculo" y la "planificación" prolongada hasta segmentos cada vez más amplios de la producción y de la economía, etc. - está excluido que todas esas funciones sean completadas por "personas" (Castoriadis, 1986: 190).

En las páginas que suceden a esta cita se profundiza el argumento que se refiere a la relación entre los revolucionarios y la clase. El análisis alcanza al propio centralismo democrático, propuesto por Lenin y considerado como una clara inclinación hacia el centralismo burocrático (Castoriadis, 1974a: 166). La consigna crítica, ${ }^{24}$ relativa a la división entre ejecutantes y dirigentes será sopesada igualmente en ese pasaje en relación con el terreno de lo social-histórico en el que tiene lugar la demarcación de la acción de los Partidos Comunistas y de su interlocución con el régimen de Stalin. Enrique Escobar (2004), miembro de $S$ ou B entre 1963 y 1967, en un texto crítico del volumen publicado por Christophe Bourseiller (2003) sobre la ultra izquierda, describe esa postura como: “El 'antifascismo' de los PC fue en lo esencial una estrategia, apuntando hacia la liquidación, como en España en 1936-1939 (que se lea Bolloten), de los movimientos revolucionarios que escapaban al control estaliniano".

Los debates en el interior del grupo $S$ ou $B$ evolucionan desde muy temprano hacia una relectura crítica de algunas de las tesis fundamentales de Marx. Esa relectura estará en el origen de la escisión del

\footnotetext{
${ }^{24}$ Fundacional, no manifiesta del colectivo $S$ ou $B$.
} 
1963, en la que J. F. Lyotard, acusando a Castoriadis de haber traicionado al marxismo, se separa del grupo. El fracaso de esa corriente de pensamiento y acción para transformar radicalmente el mundo y las interrogantes respecto de la praxis que de ella se derivan venían acompañados de una tendencia de las sociedades contemporáneas hacia la pérdida de referentes. ${ }^{25} \mathrm{El}$ propio marxismo, en su tenacidad, se transformará en credo. Mientras que las tesis principales de la infalibilidad del derrumbe del capitalismo se desmentían una a una dentro del colectivo gracias a una lectura crítica de los movimientos sociales, la tendencia al aburguesamiento de la clase obrera en los países industrializados se consolidará. Castoriadis se refiere al fenómeno de burocratización del movimiento obrero que corre paralelo a dicho aburguesamiento cuando analiza, años después, la crisis de sentido que acompaña la primera mitad del siglo $\mathrm{xx}$ :

Unida a la tendencia incontrolable de las sociedades modernas a la burocratización, que desde finales del siglo XIX penetra y domina el mismo movimiento obrero, la ortodoxia contribuye poderosamente a la constitución de Partidos-Iglesias. Conduce también a una esterilización casi completa del pensamiento. La "teoría revolucionaria" se convierte en comentario talmúdico de los textos sagrados mientras que, frente a las inmensas transformaciones científicas, culturales y artísticas que se acumulan desde 1890, el marxismo permanece sordo o se dedica a calificarlos como productos de la burguesía decadente. Un texto de Lukács y algunas frases de Trotski y de Gramsci no son suficientes para desacreditar este diagnóstico (Castoriadis, 1996b: 44).

Paralelamente a esta constatación, algunos sectores de la izquierda habían hecho la gran travesía para ir a buscar al sujeto revolucionario sustituto en las filas del campesinado del Tercer Mundo. De este nuevo viaje en búsqueda de lo perdido nacerán el fanonismo y el guevarismo.

\footnotetext{
${ }^{25}$ Con el tiempo será denominado por Castoriadis una "crisis de sentido".
}

La ruptura con la tradición marxista experimentada por una parte del colectivo $S$ ou $B$ había llegado aparejada al reconocimiento de un movimiento reflexivo en las sociedades occidentales en torno a la disolución de la fe religiosa y de las expectativas que supone la idea de una tierra prometida, incluso en el caso del positivismo científico. ${ }^{26}$ Un análisis serio del materialismo histórico y científico revelaba que ésos se habían alimentado también del aporte de la experiencia del movimiento democrático, la Revolución Francesa y de aquello que fascinaba a Marx en su juventud: la polis y el demos griegos.

El contexto de inmersión paulatina del marxismo en la socialdemocracia, visto a la luz de los términos de la escisión del grupo $S$ ou B en 1963, deja abiertas algunas interrogantes: ¿cómo se pudo hacer del pensamiento de Marx un dogma? y ¿cómo es que no ocurrió lo mismo con otros pensadores políticos, como Hobbes, Montesquieu o Toqueville? La dilucidación en torno a esas interrogantes llevaba a Castoriadis a afirmar que son los escritos de Marx que se prestan a hacer de ellos un dogma. Siguiendo el hilo conductor de este escrito, veamos cómo esa crítica y la concepción que deriva de ella se plasmarán en una práctica radical.

\section{UNA CITA CON EL POLICÍA QUE TODOS LLEVAMOS DENTRO27}

La trayectoria de $S$ ou $B$ estuvo marcada por las disensiones, que no pocas veces terminaron en rupturas. Se acerca a su fin en los últimos años de la década de 1960. En el interior del colectivo empezaba a emerger el fuerte ascendiente intelectual de Castoriadis paralelo a la relativa cesión de la función pensante en su persona y se impuso la necesidad de repensar la dimensión del quehacer transformador

\footnotetext{
${ }^{26}$ Véase, por ejemplo, la fascinación que ejercen la tecnociencia y la promesa de un mundo ideal garantizada por ella (Cabrera, 2006).

${ }^{27}$ De una escritura en los muros de París en mayo del 68, visiblemente inspirada en Mikhail Bakunin.
} 
desde la cotidianidad. Esta urgencia inspira a Castoriadis cuando, en el acta de autodisolución, habla de los suscritos a la revista, como lectores-consumidores de ideas (Lourau, 1980).

El proceso que desemboca en la autodisolución de $S$ ou $B$ pertenece precisamente a esa cultura de crítica de la vida cotidiana. Socialisme ou Barbarie desaparece como publicación en 1965 y el grupo se disuelve poco más de un año después, en 1967. En los albores del movimiento del $68,{ }^{28}$ Castoriadis emprende una reflexión que reconoce en la militancia una esfera separada que se ciega respecto de la propia institución. Uno de los desenlaces de esta tarea de crítica de la vida cotidiana será la profundización del saber y la práctica psicoanalíticos. La consigna que llevó a Castoriadis a emprender esa travesía fue: ¿cómo concebir a un revolucionario que se niega a mirar en su interior?

Esos desarrollos referidos a la importancia meridiana de la dimensión imaginaria de la sociedad para abordar las posibilidades del cambio radical ya se encontraban en germen en los debates al interior de $S$ ou $B$ y en el pensamiento de Castoriadis desde los años sesenta. En especial, era el caso de su lectura de lo social-histórico como una creación, gracias al balance de la relación entre instituyente e instituido y, en particular, al de su crítica dirigida al anhelo - lindante con el frenesí religioso mesiánico- de un sujeto revolucionario por naturaleza. Esa crítica se había topado, inevitablemente, con las contradicciones esenciales que significa - en ausencia de infalibilidad - la "necesidad" de la vanguardia inherente a la supuesta naturaleza revolucionaria. La consideración de los aportes de la obra freudiana al análisis de los fenómenos colectivos y una reflexión novedosa en torno a aquello que mantiene a la sociedad unida, es decir, su institución, estaba en curso en el periodo

\footnotetext{
${ }^{28}$ Nos dice: "Mayo de 68 corresponde más bien al orden de un evento puro, libre de toda causalidad normal o normativa. [...] Lo que cuenta es que ése fue un fenómeno de clarividencia, como si una sociedad viera de un solo golpe lo que ella contenía de intolerable y viera también la posibilidad de otra cosa". Véase Deleuze y Guatari en <www.revue-chimeres.fr/drupal_ chimeres/?q=node/87>
}

que precede a la autodisolución de $S$ ou $B$. Durante el periodo activo del grupo había influido a intelectuales de otras disciplinas, activistas, etc. En entrevista con Luis Gómez, René Lourau ${ }^{29}$ nos dice:

Luis Gómez: ¿Cómo llegaste a las reglas no escritas de la sociedad, es decir, la institución fuera y dentro de la institución?

René Lourau: En la etapa más visible, puedo decir que encontré una corriente de investigación hace unos 20 años, en un pequeño grupo opositor en la educación, también ligado a una corriente política opositora, igualmente minúscula, conocida como la revista Socialisme ou Barbarie y animada por Lefort, Lyotard y Castoriadis. En ese tiempo, al final, ya sólo la impulsaba Castoriadis, puesto que los demás se habían retirado.

Había en el grupo un conjunto de preocupaciones anti-institucionales; [...] crítica muy fuerte que se remontaba a los comienzos de la Tercera Internacional: crítica de la forma partido, de la institución partido, del partido revolucionario. Esto produjo, entre otras cosas, la crítica de la burocracia, la alternativa de la autogestión y la propuesta de los consejos obreros, así como el esquema de una nueva teoría de la institución que, forjada por Castoriadis, me ha influido enormemente. ${ }^{30}$

Para ilustrar la dimensión profunda y compleja de la relación con la institución propia - cuando está caracterizada por la heteronomía, dimensión a la que Castoriadis accederá gracias al saber y la práctica psicoanalíticos-, reproduzco a continuación la respuesta que el autor da a Daniel Mermet a propósito de esa relación para el caso de la cultura política del 68 .

Daniel Mermet: Usted ha hablado y escrito mucho sobre el movimiento del 68. Con Edgar Morin y Claude Lefort lo han denominado "la brecha" (la

\footnotetext{
${ }^{29}$ Que en el 68, desde el colectivo en torno a Henri Lefebvre en Nanterre, asistió a la formación del Mouvement 22 Mars que precedió el mayo francés y que se autodefinía como un libertario. Respecto del legado de Castoriadis sobre las nociones de base de la corriente institucionalista y en especial en relación con las posturas de Lourau. Véase <www-ufr8.univ-paris8.fr/pfa/34presentation.htm>.

${ }^{30}$ Subrayado nuestro.
} 


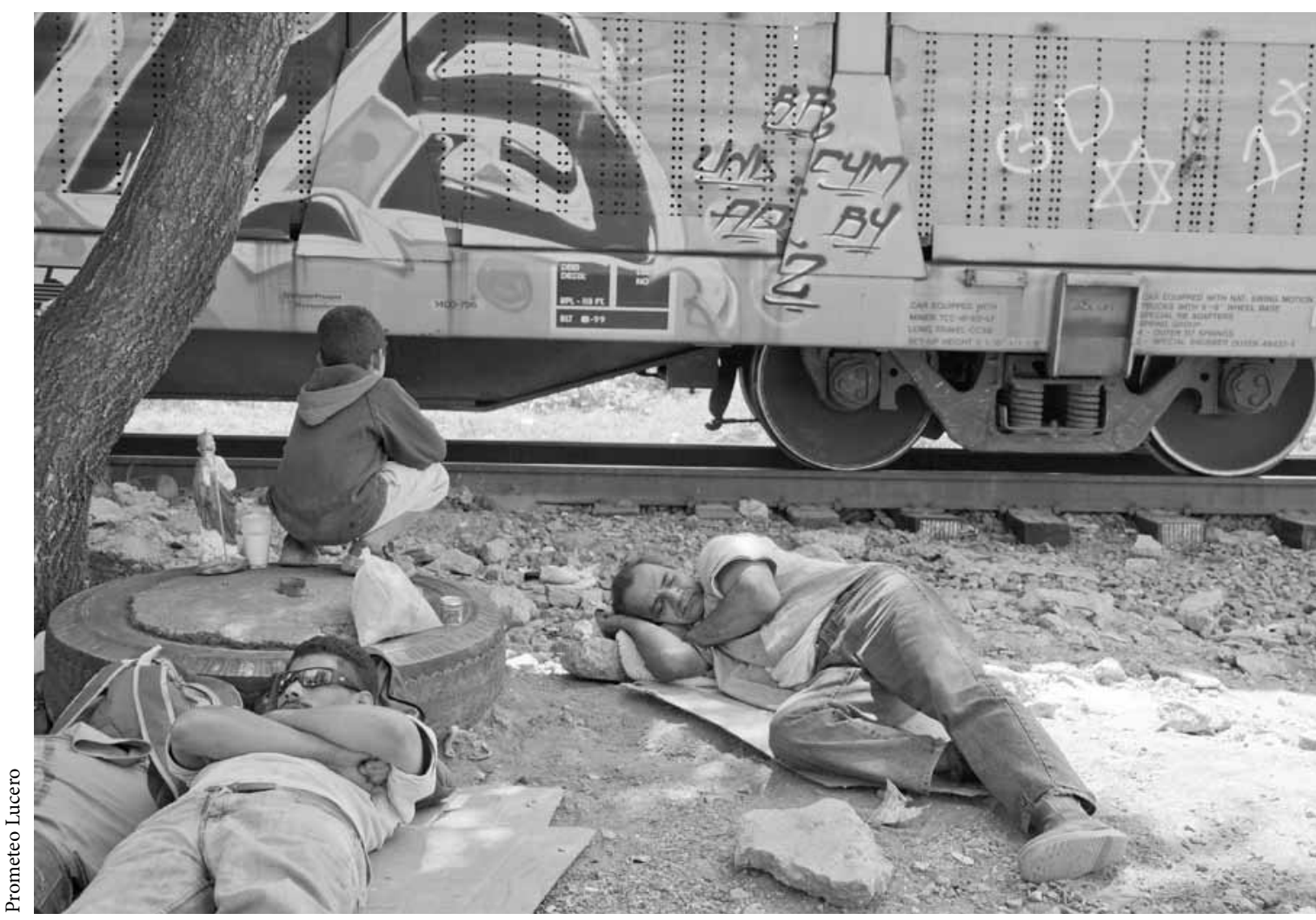

Migrantes esperan el tren en Lechería, 2011.

brèche). [...] Reflexionando de nuevo sobre esa épo$\mathrm{ca}$, nos sorprende la ceguera. Nos impactan los comportamientos revolucionarios, románticos, absolutos, doctrinales, carentes de base y en una ignorancia total respecto a cosas que era posible saber, de lo que realmente estaba ocurriendo en la China de Mao. Pero es preferible creer que saber...

Cornelius Castoriadis: En efecto, usted tiene razón desde un cierto punto de vista que es muy importante. Pero no se trata ahí de una cuestión de nivel de conocimiento, me parece. Es la enorme dominación en sentido estricto e, iba a decir, en el sentido negativo del término. No se trata de que los maoístas no sepan, se les había adoctrinado o ellos mismos se habían adoctrinado. ¿Por qué ellos aceptan el adoctrinamiento? ¿Por qué ellos se adoctrinan a sí mismos? Porque tenían necesidad de ser adoctrinados. Ellos tenían necesidad de creer. Eso, eso ha sido la gran herida del movimiento revolucionario desde siempre (Castoriadis, 2004: 29-32).

\section{EL OCULTAMIENTO DEY LA PASIÓN POR LA ALTERIDAD}

Una vez introducidos algunos rasgos inequívocos de la obra institucional de Castoriadis y del impacto que tuvo en los movimientos sociales de los años sesenta resulta más asequible entender el desenlace del grupo y la revista Socialisme ou Barbarie. Mientras que la razón de ser de ese colectivo se había conformado a partir de la crítica del fenómeno burocrático como materialización de la significación imaginaria social del dominio racional, la tendencia al interior del grupo - entre los propios activistas y de éstos en relación con los "consumidores pasivos de ideas" - evolucionaba también de manera inquietante, presumo, hacia la repetición institucional en la renuncia y hacia la heteronomía. 
La cesión de la reflexión respecto de la propia práctica y la concentración de aquélla en una sola figura daba cuenta - trágicamente- de la frecuente tendencia - no precisamente natural, aunque de una reiteración abrumadora - a depositar en el otro — dios, el partido, los representantes, los expertos- lo que en la jerga psicoanalítica se conoce como el esquema de omnipotencia, esa tendencia que tanto en la dimensión individual como en la colectiva aspira perpetuamente a ocultar la alteridad en cuanto tal. Habría que esperar varias décadas e incluso la muerte del padre para ver el desenlace de lo que - utilizando una metáfora del propio Castoriadis en torno a Freud y sus discípulos- podríamos llamar el pequeño clan castoridiano inicial. Retomo esta idea más adelante.

Vamos cerrando. Es cierto que en los mejores momentos de S ou B Castoriadis no estaba solo, fungía, en su condición de pensante, como una especie de portavoz de un colectivo que rebasaba los estrechos límites de S ou B para llegar hasta la cultura política de la extrema izquierda en la Francia de posguerra.

No obstante la constatación de esa tendencia, la autodisolución, como momento de desvelamiento de la alteridad radical, emergía impostergablemente como ejercicio extremo de la autonomía que se autolimita. El mismo gusto por la alteridad que inspiraba la transformación radical de la sociedad, en el momento de la autodisolución enfrentaba a los miembros de $S$ ou $B$ a la desaparición del sentido y a la posibilidad del sentido radicalmente nuevo. Las influencias posteriores en el mayo del 68 francés y en la corriente institucionalista llevarían también ese sello trágico.

Esa pasión por la alteridad, llevada a sus últimas consecuencias, había conducido a Castoriadis -en sus propias palabras: "absorto por el psicoanálisis" en el momento inmediato anterior a la autodisolución- al encuentro del otro que nos habita. El desenlace de esa obra institucional había explicitado una relación nueva entre lo instituyente y lo instituido vaticinándola como la esencia de la legítima voluntad de transformación de lo dado. Es esa voluntad que va al encuentro con el otro que nos habita, repito, para dirigirse sucesivamente hacia el otro que seremos cuando dejemos de ser lo que somos. Lo que siguió en la biografía del migrante Castoriadis fue el regreso a las fuentes de la tradición filosófica heredada, gracias a la herramienta representada por la noción de imaginario como creación. Ese trayecto tuvo que pasar por el desarme de la hipercategoría de la determinidad, para abrir un horizonte ontológico inédito. La ruptura de la clausura que estaba en el origen del nacimiento de la democracia y la filosofía, una ruptura por tanto abierta a la alteridad, se proyectaba considerando la modernidad conocida como un proceso inacabado y sugiriendo una segunda modernidad posible y plena.

Al mismo tiempo, el angelismo y los falsos mestizajes — de la declarada posmodernidad- venían acompañados de una tendencia fuerte y piadosa a la asimilación de "la identidad" con "la esencia": el "Occidente diabólico" y los pueblos originarios "desprovistos" de toda maldad y tan inocentes que era "necesario" protegerlos daban cuenta de las versiones actuales de los sueños pastorales, y por tanto del aumento de la insignificancia. De esta poción, resistente a la alteridad perpetua, tuvimos hasta el hartazgo. Nos la tragamos respecto de los obreros antes de que se convirtieran en burócratas de partido, de los indios antes de convertirse en caciques y machos fascinados por los artefactos, de las mujeres antes de que pasaran, algunas de ellas, a ser tenaces dirigentes de empresas y oNGs. Los campesinistas igual nos matracaron en relación con esa condición innata de sus clientelas, hasta que les salieron al paso las camionetas $4 \times 4,{ }^{31}$ los empresarios agrícolas, las motosierras y los pesticidas, y finalmente tuvimos de esa poción también en el caso de los migrantes “forzados" antes de que se entregaran al festín consumidor, la santa muerte y las maras. Estas visiones unidimensionales, antes de enfrentarse a la contundencia de la alteridad del otro que se repite y/o excepcionalmente se autoaltera, se habían desmentido una tras otra sin que nadie, o casi nadie, se hubiera preocupado por entender las razones profundas.

\footnotetext{
${ }^{31}$ Tan cotizadas en la Venezuela de Chávez.
} 
Dedico algunas líneas a pensar sobre esta negligencia frente a la urgencia de reflexionar y medir las consecuencias de ese derrumbe de certezas.

\section{LA AUTOALTERACIÓN ES EL FIN DEL PSICOANÁLISIS}

Las parodias con las que cierro el parágrafo anterior nos hablan de una tendencia, cuasi natural, podríamos decir, del observador a identificarse con el propio objeto de estudio, llámese población meta, feligreses, clientes, etc. La necesidad de creer que Castoriadis evoca en la cita en páginas anteriores tiene una validez meridiana en este aspecto. La determinidad es entonces el salvavidas de la tradición filosófica heredada y de las imposturas políticas que de ella se derivan, la determinidad de unas leyes de la historia escritas de una vez y para siempre, de la estructura y de la función. El efecto, de nuevo paródico, habría desembocado en la proclamación de la muerte de la política, del sujeto e incluso de la filosofía. Ante este panorama, el imaginario - como instancia no determinada de creación de nuevas formas, de nuevos eidos- no podía más que introducir un verdadero trastorno en la manera de pensar la ontología.

El psicoanálisis como saber, no como ciencia y como práctica poietica —esa "ciencia burguesa", como se le llamó durante décadas en medios de izquierda oficial-, venía a la revancha. Althuser había asesinado a su esposa, Toni Negri había abandonado en la cárcel a sus antiguos camaradas. El denominado pensamiento posmoderno dio la espalda a la política por considerarla fuente inevitable del totalitarismo y se desarrolló un psicoanálisis en la pretensión de estar al margen de "la política" donde el sujeto era tal por estar "sujetado". ${ }^{2}$ Muy preocupado por su clínica, antes de que viniera la crisis del pase y la constatación de

\footnotetext{
32 En entrevista reciente (2011), Eduardo Colombo establece un vínculo estrecho entre el auge de la práctica y la teoría psicoanalítica en versión de Lacan y el periodo sucesivo a la toma del poder de los militares en la Argentina.
}

que un director de sociedad psicoanalítica podría convertirse en una versión "ilustrada" de secretario de partido, ese psicoanálisis se había convertido en una ideología reaccionaria.

Curiosamente, sería una versión del propio psicoanálisis - versión fiel a la concepción del imaginario en su condición de lugar en el que emerge la representación como presentación, es decir, como creación - en su vocación por la autonomía, al interior de la cual se advertiría del significado profundo del derrumbe de las viejas certezas inamovibles que lindan con la nostalgia de un Estado donde no hay contradicción y que remite ineluctablemente a la repetición institucional. El entonces Cuarto Grupo, animado por la psicoanalista milanesa Piera Aulagnier, retomaba los desafíos de esa nueva concepción del imaginario y de lo social-histórico inaugurando una obra institucional radical:

toma cuerpo la idea de un Cuarto Grupo. Éste conserva una parte de la herencia lacaniana, pero la "corrige" con un enfoque sociológico. En vez de títulos encontramos funciones, papeles o calificaciones; en lugar de un nombramiento simbólico se prefiere una circulación imaginaria de las situaciones; y a guisa de prueba de paso adquiere valor el hecho de que el grupo se haga cargo del devenir analítico de los individuos. Mediante estos principios, el Cuarto Grupo será la única institución de la Francia freudiana que pondrá en acto, en sus estructuras mismas, una enseñanza originada en la psicología social y en cierta tradición culturalista (Rudinesco, 1993: 93).

$$
\propto \text { 䂧 }
$$

Después de este rodeo regreso a mi idea original. La biografía de Castoriadis no ha sido escrita todavía. Estoy seguro, como de hecho se sugiere en el coloquio que refiero en líneas anteriores, que su condición de metec $^{33}$ añade otro ingrediente a su singular

\footnotetext{
${ }^{33}$ Expresión despectiva en sus orígenes para referirse a los extranjeros en el mundo francófono. Después fue reivindicada por una cierta cultura alternativa.
} 
trayectoria. El evento del padre expulsado de Francia tuvo un signo definitivo. La ulterior clandestinidad del hijo Cornelius - los militantes radicales del 68 en Francia y en Europa admiraban y leían ávidamente a Chaulieu $^{34}$ sin imaginarse que se trataba, precisamente, de Castoriadis-, su decisión final de dejar de ser funcionario de la Organización para la Cooperación y el Desarrollo Económico (OCDE) y de naturalizarse francés eran igualmente pasajes definitivos. ${ }^{35}$

En este hacer pensante está en juego la condición compartida por tantos sujetos anónimos y por tantas sociedades-sujeto que, en casos excepcionales, se ligan a la búsqueda explícita de un proyecto de sociedad distinta. Castoriadis falleció a finales de 1997, los desencuentros respecto de su legado, de lo chusco a lo trágico y de ahí a lo grotesco, han sido por demás abundantes y muy analizadores. Hoy, el padre está muerto, para usar de nuevo la metáfora inspirada en Tótem y tabú (Freud, 1994), la democracia primitiva de los hermanos es todavía una asignatura pendiente.
En la introducción de la recién publicada traducción al italiano (2010) del debate que Castoriadis sostuvo con el Movimiento Anti-utilitarista en Ciencias Sociales (MAUSs) salta a la vista un interesante capítulo de la trayectoria de nuestro filósofo ciudadano, polifacético cosmopolita: se trata de la cuestión de la técnica. Castoriadis había escrito para la Enciclopedia Universalis el emblemático artículo denominado “Technique" (1978). La reflexión filosófica que emprende en ese espacio tiene consecuencias de proporción que vinculan la cuestión de la búsqueda de verdad con la autotransformación de la sociedad. La fascinación que la técnica ha ejercido en la historia

\footnotetext{
${ }^{34}$ Además de este seudónimo, Castoriadis utilizó los siguientes en distintas épocas: Paul Cardan, Jean-Marc Coudray, Jean Delvaux y Marc Noiraud.

${ }^{35}$ Véase <www.agorainternational.org/es/esccaiint.pdf $>$.
}

de la humanidad nos habla de los procesos identificatorios respecto del propio objeto de estudio que hemos evocado. Creer en la omnipotencia de la técnica es una forma más de ver en la institución una instancia mítica y de depositar en ella el único esquema que la psique conoce en estado monádico. La técnica en el mundo de la tradición filosófica y las denominadas ciencias sociales se intercambia por la estructura, la función, la determinación finalmente. ¿Cómo aspirar a aprehender la complejidad de lo social cuando, una y otra vez, lo que queremos no es saber sino creer?

La respuesta está en la dirección de la obra institucional por la autonomía que es a su vez del orden no de la episteme, sino de la política en sentido noble. Irónicamente y no sin cierto bochorno respecto de las filiaciones del término con la Ilustración (véase la cuestión del contrato social), creo que esa obra institucional está hoy fincada sólidamente en una manera distinta de entender el servicio público ${ }^{36}$ desapegado del Estado y en manos de colectivos anónimos que operan, no en el ámbito que opone sociedad civil a sociedad política, sino en aquel desde el cual se reivindica el espacio de lo privado-público, el ágora, como lugar de ejercicio del infrapoder, el poder instituyente. Ajeno a la filantropía y a toda cultura pastoral, la nueva forma de entender el servicio público nos da la pauta para recuperar los momentos en los que la sociedad todavía quiere ser sociedad y en los que deja de ser lo que es porque quiere ser otra cosa.

Castoriadis era el sujeto en tránsito que predicaba con el ejemplo, como hemos tenido la oportunidad de ilustrar, en el sentido de la coherencia con el proyecto que subyace a esa visión del servicio público. Sabemos que la revista Socialisme ou Barbarie. Organe de critique et orientation révolutionnaire era financiada de manera importante con el sueldo que Castoriadis ganaba como funcionario internacional en la ocDE. Su desprendimiento total de

\footnotetext{
${ }^{36}$ A pesar de que este término y la práctica a la que se refiere también encuentran un sólido soporte en las ideas de apoyo mutuo provenientes de la tradición libertaria.
} 
comunicaciones personales respecto de los derechos de propiedad de su obra era otro elocuente aspecto de la obra institucional inspirada en esa filosofía del servicio público. Sabemos por testimonios directos que su práctica psicoanalítica transitaba a menudo por las cuestiones cruciales de la gran política y la filosofía. Por último, su empatía con la posibilidad de abrir un espacio electrónico para dar a conocer su obra escrita haciendo uso de los nuevos recursos tecnológicos iba en el mismo sentido. Me detengo para ejemplificar, a modo de cierre, algunos aspectos referidos a esa vía del servicio público como condición sine qua non de la transformación por la sociedad contemporánea de sus propias instituciones.

\section{VIVIR CON LA ALTERIDAD SE LLAMA POLÍTICAY ES UNA TRAVESÍA}

En su importantísimo texto “Tiempo y creación", Castoriadis (1990b) estudia la cuestión de la emergencia perpetua del tiempo como alteridad y la posiciona frente al tiempo calendario. Esas dos dimensiones de lo "conjuntante identificante" y de lo propiamente imaginario, de la repetición y la creación, de la identidad y la alteridad - se es lo que se es, pero también, al mismo tiempo, se es lo por ser-, siempre prevalecen en la discusión en torno al tiempo. El tiempo como emergencia perpetua es inseparable del ser y de la historia como creación:

Por ahora yo afirmo que hay ser como sujeto o que hay seres que son sujetos, es decir que son para sí mismos. Por ejemplo: nosotros. Pero un sujeto no es nada si no es la creación de un mundo para él en una relativa clausura (Castoriadis, 1990b: 308-309).

Esta multiplicidad (la creación es siempre creación de multiplicidad) se desarrolla siempre sobre dos modos: el modo de lo simplemente diferente, como diferente, repetición, multiplicidad ensídica [ensembliste-identitaire es decir conjuntista-identitaria, Miranda]; y el modo de lo otro, como alteridad, emergencia, multiplicidad creadora, imaginario o poietico (Castoriadis, 1990b: 308-309).

Ahora bien, en el campo de lo social-histórico conocido sólo excepcionalmente las sociedades han asumido la alteridad y con ella la autocreación explícita. La regla es exactamente lo contrario, es decir, las sociedades históricas en su enorme mayoría han ocultado la alteridad detrás de la creencia y la repetición. Una visión de la migración en los términos de dicha creencia subyace a la noción de migración forzada. Perteneciente a la categoría de las metanormas, la llamada migración forzada en su pretensión de infalibilidad estaría en el elenco propio de las leyes de la historia, las leyes del mercado y así sucesivamente, y las variantes sólo serían las excepciones que confirman la regla. Pero la realidad de la migración, en su dimensión ontológica espacio-temporal, su dimensión de código y su dimensión propiamente imaginaria, es mucho más compleja. Pretender simplificar dicha complejidad es un esfuerzo candoroso, por decir lo menos, que nos revela la nostalgia de clausura de quien emprende ese ejercicio. Nos habla finalmente, y aquí el gran aporte de Castoriadis, de la relación de cada sociedad frente a su institución. Quien habla de la migración y quien migra, a menudo dos sujetos diferentes son la medida de ese abismo que se ensancha, hacer pensando la migración es el momento de la complejidad y del rebase de la determinidad.

Ocultar la alteridad que significa el eterno devenir u ocultar la emergencia perpetua del ser como creación equivale a hacer de la identidad, de nuevo, algo esencial. Esencializar la identidad -o pensar sin separarse de la hipercategoría de la determinidad - no sólo niega la alteridad, sino que se encierra en la repetición. Ser indio, ser mujer o proletario, ser migrantefinalmente ¿es una condición unidimensional? Claramente, la respuesta es no. ¿Cómo tratar esa escisión del sujeto que se sabe como tal, que por momentos excepcionales se revela ante lo dado y que en general se acomoda en lo familiar? Hemos delineado algunas pistas para dar respuesta a esta interrogante al analizar la trayectoria de la cabeza visible de 
un colectivo llamado Socialisme ou Barbarie que se abrió ante la alteridad, como lo hace quien se prepara para una gran travesía.

Sabemos, por otro lado, que la autonomía no es un valor universal y no puede enseñarse. ¿Cómo lidiar entonces con dicha escisión del sujeto y con la condición perpetua del imaginario que una vez crea y otra repite? No hay respuesta a esta pregunta más que en el campo de la práctica poietica por medio de la cual el sujeto - el sujeto del psicoanálisis pero también la sociedad como sujeto- hace explícita la transferencia, deja de ver en la propia institución una instancia mítica y entonces renace como sujeto autónomo. Es esa práctica poietica lo que llamo la obra institucional por la autonomía. Sostengo entonces que la esencia del acto de autodisolución de $S$ ou $B$ es un acto de explicitación de la transferencia respecto de la propia institución - llámese cultura de izquierda radical, "revolución", definitivamente determinidad o traslado del esquema de omnipotencia hacia el otro- $y$ en ese sentido es un acto de ejercicio de la autonomía llevado al extremo.

Hago de nuevo un rodeo para cerrar con alteridad radical y migración. En una enorme mayoría de casos la decisión de migrar conlleva una serie de variables tanto del orden de lo querido, lo consciente, como del orden de lo latente, de lo inconsciente. Dejando de lado las modalidades ligadas a la sobrevivencia ante la violencia extrema, la frecuencia con la que - en la forma más masiva y contemporánea de la migración - un halo heroico envuelve ese acto iniciático en las comunidades tradicionales es apabullante. Luego, claro está, muchos miembros de la familia ${ }^{37}$ cercana al "elegido" van a comprometer recursos financieros y otros. Finalmente, la cadena se cierra con la aportación masiva a la industria del tráfico de personas, que indudablemente el sistema mantiene en operación. ¿En qué medida este tipo de migración implica una toma de distancia respecto de las instituciones de la cultura de origen y por tanto abierta al cambio?

\footnotetext{
${ }^{37}$ En su contexto, nunca de las más pobres, ni de recursos financieros ni de redes sociales.
}

Castoriadis (1990a) nos habla del silogismo del sujeto que profesa "yo estoy bien, soy el bien, tú no eres yo, por tanto tú no estás bien, tus dioses no son verdaderos..." cuando ilustra las maneras en que las culturas de los pueblos se interrelacionan. De modo sintético, habría dos fórmulas vinculantes, una improbable y otra excepcional. En las dos primeras se percibe algo inferior en la cultura del otro, lo que sucede en la mayoría de los casos. La segunda consiste en lo contrario: algo superior se ve en la cultura del otro, lo que ocurre en muchos procesos de transculturación y mestizaje verdadero o falso. La tercera supone que algo igual se ve en la cultura del otro, lo que es muy improbable porque si la cultura del otro es igual a la propia, el otro no es otro. Esas opciones se dirimen entre repetición y creación de sentido. La última posibilidad, cuya excepcionalidad en la historia es notable, consiste en ver en el otro, simplemente otro. Esta postura supone no sólo la posibilidad de la alteridad, el otro es como otro, sino incluso su valoración. ${ }^{38}$ La ruptura de la clausura frente a la creencia en los dioses, en la costumbre, en los antepasados, en las leyes de la historia y en el mercado se funda en esa condición por excelencia que valora la alteridad. Se trata de una valoración que profesa, siendo fiel a su —si se me permite- excepcional tradición: "queremos dejar de ser lo que somos porque queremos ser otra cosa".

El Castoriadis migrante era un explorador de la libertad. Como figura prominente de un colectivo llamado Socialisme ou Barbarie tuvo también el coraje - precisamente ajeno a todo angelismo- de enfrentar la alteridad extrema que conlleva la desaparición del sentido y disolvió esa organización con sus camaradas. Para algunos esta autodisolución fue un error

\footnotetext{
38 ¿Por qué los pueblos "no occidentales", renunciando a los lazos sociales tradicionales y a sus ancestrales culturas, se apropian de los aspectos más perniciosos del Occidente moderno - las ametralladoras, los carros blindados, los gadgets de la tecnociencia o el fanatismo futbolístico- e ignoran los aspectos más positivos de esa tradición, como el amor por la libertad y la curiosidad por el otro como otro? Es una interrogante que inquietaba a Castoriadis. Documentar esta cuestión, como mínimo, representa para nosotros un verdadero desafío.
} 
y un desenlace desagraciado; ${ }^{39}$ para otros, los menos, significó la reiteración de aquello que viene aparejado a la democracia radical como régimen de ejercicio de la autonomía ante la alteridad perpetua, que es su carácter trágico.

$$
\propto
$$

Todavía en vida, Castoriadis tuvo conocimiento del proyecto de creación de una arena pública en la nueva realidad del ciberespacio. Un ágora virtual donde llegaran a discutir todos aquellos para quienes el proyecto de autonomía es algo por lo que vale la pena trabajar. Cornelius Castoriadis/Agora International (CC/AI) nace - de nuevo- gracias a la iniciativa de un colectivo compuesto por migrantes en Francia. Ramin Jahanbegloo, Canadá-Irán; Zarir Merat, Irán; Clara Gibson Maxwell, Estados Unidos; David Ames Curtis, Estados Unidos, habían fundado la asociación. El portal electrónico correspondiente - una vez que los dos primeros se retiraron-, <www.agorainternational.org $>$, fue patrocinado y alojado por las bibliotecas de la Universidad de Michigan y Beau David, bibliotecario de campo para estudios clásicos con la Asociación -Asociación Ley 1901 registrada en Francia- $C C / A I^{40}$

Después de su creación, $C C / A I$ fue integrando un colectivo de bibliógrafos que operan inspirados en la filosofía del servicio público. Actualmente el portal cuenta con 17 bases de datos bibliográficos y concentra gran cantidad de materiales en formato electrónico, mismos que son puestos a disposición de sus usuarios, en el mismo número de idiomas. La información que dicho colectivo de bibliógrafos está generando, a partir de los nuevos eventos en torno a la obra escrita e institucional de Castoriadis, es distribuida electrónicamente a un directorio de más de

\footnotetext{
${ }^{39}$ En comunicación personal con algunos militantes de la extrema izquierda en Estados Unidos.

${ }^{40}$ Quien escribe este texto es parte del colectivo de bibliógrafos desde 2001.
}

1600 destinatarios en el mundo. Dichos materiales incluyen la incorporación progresiva que prevé el proyecto independiente "soubscan" de los números de la revista Socialisme ou Barbarie. Desde el anonimato, CC/AI se ha consolidado en el tiempo como un lugar de referencia documental pero, cada vez más, en el sentido de su obra institucional por la autonomía.

Esta obra para el caso de Cornelius Castoriadis - es decir, lo que él hizo - ha sido vasta, aunque reina un relativo desconocimiento de la misma. $\mathrm{Su}$ obra escrita sigue siendo objeto de traducciones a diversos idiomas. Desde el portal Agora International hay la certeza de que algo tan básico como brindar un servicio público, poniendo a disposición de usuarios en todo el mundo los textos de y sobre Castoriadis, constituye una clara postura política en sentido radical. Otros proyectos paralelos, como la sección que recoge las experiencias de enseñanza ${ }^{41}$ no sólo en medios académicos, persigue ese mismo objetivo.

Esta obra institucional aspiraría a representar una tradición que en el siglo xx había inaugurado el grupo $S$ ou $B$ al poner en entredicho la institución que estaba en su origen, la "transformación del mundo" por obra del desarrollo de las fuerzas productivas. Esa tradición inspiró los mejores momentos del mayo del 68 francés (Morin, Lefort y Coudray - seudónimo de Castoriadis-, 1968, y Castoriadis, 1988), hoy representa un recurso para reivindicar la política que no es la fuente del totalitarismo irremediable ni el oficio de expertos y representantes. Finalmente, esa obra institucional aparta la centralidad de la economía, prevaleciente en nuestra sociedad capitalista y en la sociedad de capitalismo burocrático que fue la hoy ex Unión Soviética, y teje los lazos de un mundo otro que se reclama del orden de la filia, el afecto en sentido fuerte y el reconocimiento recíproco.

Se trata de una obra cuyo desarrollo y consolidación tiene lugar en el anonimato y por la acción de un colectivo, si bien sus resultados se asocian por momentos a uno u otro nombre. Es una obra que tiene que lidiar con la repetición institucional tanto

${ }^{41}$ Teaching Castoriadis. Véase $<$ www.agorainternational.org $>$. 
en su interior como en su exterior y que reconoce por tanto y trabaja en el sentido del ejercicio de la autonomía como autolimitación. Es también la obra de quienes se han desplazado y se siguen desplazando en el espacio, el geográfico y el imaginario, animados por ese deseo de dejar de ser lo que son para ser otra cosa. Ese querer ser otra cosa que, en el caso que nos ha ocupado en estas líneas, quiere decir abrirse a la alteridad y ser autónomos ante ella.

\section{Bibliografía}

Archipiélago, Cuadernos de Crítica de la Cultura, 1996, Formas del exilio, núm. 26-27, Barcelona.

Bourseiller, Christophe, 2003, Histoire générale de l'ultragauche. Situationnistes, conseillistes, communistes de conseils, luxemburgistes, communistes de gauche, marxistes libertaires, communistes libertaires, anarchistescommunistes, néo-anarchistes, gauches communistes, Denoël impacts, París.

Cabrera, Daniel, 2006, Lo tecnológico y lo imaginario. Las nuevas tecnologías como creencias y esperanzas colectivas, Biblos, Buenos Aires.

Castoriadis, Cornelius (Jean-Marc Coudray, seudónimo), 1968, "Mai 68: la brèche. Premières réflexions sur les événements", en Edgar Morin, Claude Lefort y JeanMarc Coudray, La révolution anticipée, Librairie Arthème Fayard, París, pp. 89-142, en línea: <www. magmaweb.fr/spip/spip.php?article2> y <www.magmaweb.fr/spip/IMG/pdf_Mai68LaRevolutionAnticipee_Castoriadis_-2.pdf $>$.

$\ldots$, 1974a, "Entretien avec Cornelius Castoriadis", 26 de enero, en Agence de Presse «Libération», Basse Normandie, París.

__ 1974b, "La vie de notre groupe", en L'Expérience du mouvement ouvrier, p. 163.

__ 1978, «Technique», en Les carrefours du labyrinthe, Éditions du Seuil, París pp. 221-248.

— 1986, "Tiers monde tiermondisme et democratie", en Domaines de l'homme, París, pp. 128-138.

__ 1990a, "Réflexions sur le racisme", en Le Monde morcelé, París, pp. 29-46, en línea: <red.pucp.edu.pe/ ridei/buscador/files/93.pdf>.

_ 1990b, “Temps et creation", en Le Monde morcelé, París, pp. 307-348.

_ $1996 \mathrm{a}$, "Un monde à venir. Entretien avec Olivier Morel", transmitida el 18 de junio de 1993 por Radio
Plurielle, en La montée de l'insignifiance, París, pp. 82102, en línea: <1libertaire.free.fr/castoriadis06.html>.

— 1996b, "Marxisme-leninisme la pulverisation", en La montée de l'insignifiance, París, pp. 38-51.

- 2004, entrevistas con Daniel Mermet: "Dialogue" y "Corneille, dissident essentiel", en línea: <www. costis.org/x/castoriadis/montee.htm $>$ y $<$ llibertaire. free.fr/Castoriadis $12 . \mathrm{html}>$.

- 2010, Relativismo e democrazia, dibattito con il MAUSS, Per Eleuthera, Milán.

—_, Edgar Morin y Claude Lefort, 1988, Mai 68: la brèche suivi de Vingt Ans après, Éditions Complexe, París.

Deveraux, Georges, 1980, De l'angoisse à la méthode dans les sciences du comportement, Flammarion, París.

Escobar, Enrique, 2004, "Réponse d’Enrique Escobar", en À Contre Temps. Bulletin de critique bibliographique, 18 de octubre, pp. 20-21, en línea: <www.plusloin.org/ ac/article.php3?id_article=54> y <acontretemps.org/ IMG/pdf/AC16BourseillerEscobar.pdf >.

Freud, Sigmund, [1912-1913] 1994, Tótem y tabú, en Obras completas, vol. XIII, Amorrortu, Buenos Aires, pp. 1-165.

Gottraux, Philippe, 1997, Socialisme ou Barbarie: un engagement politique et intellectuel dans la France de laprèsguerre, Éditions Payot Lausanne, Lausana.

_ 1997b, "Socialisme ou Barbarie. Une revue iconoclaste dans la France de l'après-guerre", en La Revue des revues, núm. 23, pp. 43-68, en línea: <www.plusloin.org/textes/sob.html $>$, <raforum.apinc.org/article. php3?id_article $=1798>$ y $<$ mondialisme.org/article. php3?id_article $=129>$.

_ 2002, "Socialismo o barbarie, una revista iconoclasta en la Francia de posguerra”, en Archipiélago, núm. 54.

Lourau, René, 1980, Autodissolution des avant-gardes, Éditions Galilée, París.

—_ 1987, "Las universidades sólo pueden estallar", entrevista a René Lourau por Luis Gómez, en Unomásuno, Suplemento Cultural Sábado, 17 de febrero, p. 15.

$\ldots, 1987 \mathrm{a}$, "Balance de la intervención socioanalítica”, en Felix Guattari et al., La intervención institucional, Plaza y Valdés, México.

Marx, Carlos y Federico Engels, [1848] s/f, "Manifiesto del Partido Comunista", en Obras escogidas, Editorial Progreso, Unión de Repúblicas Socialistas Soviéticas.

Reynaud, Michel y Véronique Olivares Salou, 2007, "Le Roman des Glières. La resistance des républicains espagnols au Plateau des Glières-Les maquis espagnols", en Haute-Savoie, 1941-1944, Editions Tirésias, París.

Roudinesco, Élisabeth, 1993, La batalla de cien años. Historia del psicoanálisis en Francia, Fundamentos, Madrid. 